\title{
La industria lechera en los estados del norte, desarrollo y limitaciones
}

\author{
M. del Carmen del Valle Rivera \\ Instituto de Investigaciones Económicas \\ Universidad Nacional Autónoma de México
}

\begin{abstract}
Resumen
Este trabajo tiene por objeto presentar una caracterización del proceso de producción y consumo de leche y sus derivados, e identificar algunos problemas sobresalientes. Se tratará de plantear algunos aspectos relevantes de la expresión de dicho proceso en los estados fronterizos del norte del país. Esta problemática se centra en la insatisfacción del consumo; lo cual tiene su origen, por una parte en que la producción interna es deficitaria, por lo que las importaciones de este producto han aumentado de manera notable. En las ciudades fronterizas se presenta un volumen representativo de importaciones de alimento debido a la desarticulación de la zona con los centros productores, por no haber restricciones para su importación y por las ventajas en cuanto a calidad. Por otro lado, no se trata sólo de un problema de oferta, sino que el bajo consumo de este alimento está estrechamente relacionado con el ingreso de la población.
\end{abstract}

Palabras clave: industria lechera, desarrollo, ciudades fronterizas, importación de leche, poder adquisitivo.

\begin{abstract}
This project offers a detailed explanation of the process of production and consumption of milk and dairy products that will help to identify some of the most critical problems and some outstanding aspects that explain said process in the border states of the North of Mexico will be discussed. The focus of these problems is the non-satisfaction of the consumers; whose origins are, in one hand, on the fact that domestic production is not sufficient, resulting on the fact that importing of this product has been increased in the last years. Border cities present a notorious volume of food importing due some factors: the border zone does not have good communication to the production centers; there are not importing restrictions; imported product has the advantage of having a better quality. On the other hand, this is not a problem of offer, but the low consumption of this product is closely related to the low income of the people.
\end{abstract}

Keywords: dairy industry, development, border cities, importation of milk, purchasing power. 


\title{
LA INDUSTRIA LECHERA EN LOS ESTADOS DEL NORTE, DESARROLLO Y LIMITACIONES
}

\author{
Por \\ M. del Carmen del Valle Rivera*
}

\section{PRESENTACION}

Este trabajo tiene por objeto presentar una caracterización del proceso de producción y consumo de leche y sus derivados, e identificar algunos problemas sobresalientes. Debido al interés específico que tiene esta reunión, se tratará de plantear algunos aspectos relevantes de la expresión de dicho proceso en los estados fronterizos del norte del país (EFN). 1

En términos generales, la problemática de la leche se centra en la insatisfacción del consumo; lo cual tiene su origen, por una parte, en que la producción interna es deficitaria, por lo que las importaciones de este producto han aumentado de manera notable. Conviene hacer notar que en las ciudades fronterizas se presenta un volumen representativo de importaciones de este alimento debido a la desarticulación de la zona con los centros productores, por no haber restricciones para su importación y por las ventajas en cuanto a calidad.

Por otra parte, cabe destacar que no se trata sólo de un problema de oferta, sino que el bajo consumo de este alimento está estrechamente relacionado con el ingreso de la población.

\section{LA LECHE, ALIMENTO BASICO O PRODUCTO SUNTUARIO}

La leche de vaca es un alimento con un alto valor nutritivo en el desarrollo del ser humano que eleva la calidad de la dieta alimenticia. En consecuencia, está considerada como un producto básico; indispensable en el niño para apoyarlo en su crecimiento, también en las madres gestantes o en período de lactancia y, en los ancianos; el resto de la población puede tomar las proteínas de la leche, a través del consumo de otros alimentos, por lo tanto pueden excluirse de la ingestión de este líquido. La leche se considera, además, un bien salario, porque constituye una parte importante del gasto en alimentos de la población trabajadora, urbana fundamentalmente.

\footnotetext{
- Investigadora asociada en el Instituto de Investigaciones Económicas de la UNAM; adscrita al área de fomento económico.

${ }^{1} \mathrm{Se}$ ha denominado así a los estados siguientes: Baja California, Sonora, Coahuila, Nuevo León y Tamaulipas.
} 
En nuestro país, en los momentos actuales, se observa que ha bajado la calidad de vida de la población y, en particular, los infantes han resentido con más violencia el peso de la crisis.

En estas condiciones se presenta un consumo de leche deficitario; veamos: la Organización Mundial para la Agricultura y la Alimentación (FAO), recomienda un consumo de 500 mililitros de leche por persona, al día. En México el consumo promedio fue hacia 1980 , de 340 mililitros, según el Instituto Nacional de la Leche (INL). En los estados del Norte cl consumo promedio tluctuó entre 131 y 248 gramos; ${ }^{2}$ además, en Coahuila y tamaulipas entre el 25 y $40 \%$ de la población no toma leche; en las mismas condiciones está el $25 \%$ de la población de Baja California, Chihuahua, Nuevo León y Sonora.

Ahora bien, junto a esta carencia de disponibilidad del producto, a pesar del aumento en las importaciones (cuadros 1 y 2 ), la diesigualdad en el ingreso se expresa también en la desigualdad alimentaria. Así tenemos que alrededor de un $40 \%$ de la población no toma leche; los adultos consumen el $65 \%$ del total y sólo el $47 \%$ de la población del paŕs, la que se ubica en el área urbana, consume $70 \%$ de la leche disponible, en detrimento de la población rural.

Se observa finalmente, que las formas en que se consume en mayor medida este alimento son leches higienizadas; pasteurizada y rehidratada y leche bronca o fresca que no tiene ningún control sanitario (cuadro 5). En $\mathrm{cl}$ primer caso se trata de los productos de la rama de menor precio. La leche pasteurizada es con respecto a los demás productos lácteos la que tiene un precio menor; sin embargo, a pesar de que su precio está sujeto a control por parte del gobierno desde 1974, los aumentos han tenido el siguiente comportamiento: de 1976 a 1979 fueron menores al salario mínimo; a finales de ese año, sube cl precio a $22 \%$ y cn marzo de 1980 sc eleva $10 \%$ más, mientras que el salario sólo aumenta en $18 \%$ en el mismo lapso. A partir de entonces los aumentos en el precio de la leche se han dado dos veces al año y en proporción superior al salario. En estas condiciones se observa la tendencia a convertirse en lugar de bien básico en bien suntuario. ${ }^{3}$ Sólo la leche rehidratada se encuentra al alcance de los grupos de bajos ingresos y es precisamente a ellos, que se destina, pero es insuficiente, sólo abarca zonas marginales de cinco ciudades y genera limitaciones y consecuencias que merman la economía del país, como son la acentuación de la dependencia del exterior en materia alimentaria y su contribución al desequilibrio de la balanza de pagos.

\footnotetext{
22a. Encuesta Nacional de Alimentación SAM SSA.CONACYT-COPLAMAR INL, 1979.
} 
En cuanto a la leche bronca, los elementos que determinan su mayor ingestión son su accesibilidad en zonas marginales, así como hábitos de consumo.

En lo relativo a la leche industrializada en sus diversas presentaciones y los derivados lácteos, si bien son productos nutritivos, cuya calidad alimenticia varía según el contenido de nutrientes, su relación con el ingreso de la población es directa; su consumo se inicia a partir de ingresos medios y aumenta de acuerdo con el volumen de ingreso, siendo los más altos niveles correspondientes a los más altos ingresos.

Los quesos y requesones de elaboración artesanal son los únicos derivados lácteos que son adquiridos hasta por los grupos de menores ingresos, debido a su precio reducido, pero en una proporción inferior a la leche fluida (cuadro 5). Asimismo, las leches en polvo para niños llegan a grupos de bajos ingresos porque constituyen una prestación social en algunos trabajos.

\section{TENDENCIA EN EL USO DE LA LECHE}

El desarrollo de la industria de derivados lácteos y de leches industrializadas profundiza la falta de disponibilidad para el consumo de leche higienizada, ya que se amplía su uso como materia prima en la elaboración de productos cuyo precio está liberado. De esta forma, este sector de la rama está en condiciones de obtener una mayor rentabilidad por su producto final y, por lo tanto, tiene posibilidad de pagar un poco más sobre el precio establecido a la materia prima, y absorber un mayor volumen de este líquido.

Al respecto, en la década de los setenta se aumentó la producción de queso, crema y mantequilla, y aparecen nuevos productos comerciales como yogurts, flanes, dulces etc. (cuadro 15). En la elaboración de estos productos no se utiliza sólo leche fresca como materia prima, sino también leche en polvo de importación (cuadros 3 y 4).

También las empresas dedicadas a pasteurización han ampliado sus actividades hacia la elaboración de derivados; es el caso de Pasteurizadora La Laguna; Ganaderos Productores de Leche Pura e incluso otros más, que han cambiado de giro dedicándose únicamente a la elaboración de derivados.

Otra tendencia que es importante destacar, es el marcado aumento del aumento del consumo de la leche bronca cuyas condiciones de venta son inadecuadas desde un punto de vista sanitario, ya que se presenta adulterada y a precios más altos. Esta forma de distribución abarca no sólo zonas rurales

3Datos del Instituto Nacional de la Leche y SARH, así como de la Comisión Nacional de Salarios Mínimos y Banco de México. 
alejadas, sino que cubre también áreas marginales de las ciudades. Este comportamiento está ligado al hecho de que la leche bronca se mueve en un mercado libre de control sanitario y de control de precios.

\section{CARACTERISTICAS DE LA PRODUCCION E INDUSTRIALIZACION DE LA LECHE Y SUS DERIVADOS}

En términos generales, se considera que el desarrollo de la fase de transformación en el sistema leche ha constituido un elemento fundamental en el crecimiento de la actividad pecuaria en materia de leche.

Así, observamos que en los años cuarenta y principios de los cincuenta el Estado aplica programas de apoyo para mejorar la actividad agropecuaria, consistente en créditos para adquisición de ganado, servicios sanitarios, instalaciones más modernas y asistencia técnica agrícola y ganadera. Asimismo, se fomentaba la instalación de empresas dedicadas a la industrialización. 4

En esos años se instalan plantas de dos empresas extranjeras de gran importancia en el mercado mundial de alimentos, filiales de las firmas Nestlé Alimenticia (Suiza) y Carnation Corporation (estadounidense), y que se dedicaban inicialmente a la producción de leche evaporada, condensada y en polvo.

En cuanto a la leche fluida, hacia los años cincuenta se da un fuerte impulso a la producción primaria de leche, así como a las cmpresas pasteurizadoras, a través de programas de apoyo a la producción de leche, financiados por el Fondo de Garantía y Fomento para la Agricultura, Ganadería y Avicultura en México. Con este programa se beneficia a la cuenca lechera de la Comarca Lagunera y Delicias, Chihuahua.

La empresa Pasteurizadora Laguna, S.A., que inició sus actividades en esa zona en 1952, al tener acceso a amplios volúmenes de leche fluida se desarrolla constituyéndose en un complejo de plantas pasteurizadoras y de empresas que complementan esta actividad, integrada directamente con la producción primaria.

Así, la aparición de agroindustrias, junto con la política de fomento a la ganadería por parte del Estado, han propiciado un desarrollo y modernización en la actividad pecuaria, de modo que se da lugar al establecimiento de explotaciones con ganado estabulado, que obtienen un mayor nivel de productividad. Sin embargo, la presencia de formas tradicionales de producción primaria prevalecen.

${ }^{4}$ Loredo Goytorlúa Joaquín. "Producción y productividad agrícola", en: La ganadería en México. 50 años de revolución. FCE 1960, pp. 132-138. 
La agroindustria de lácteos en su conjunto ha sido una actividad dinámica (cuadro 15a y b); sin embargo, hay diferencias notables de comportamiento según la línea de producción; de ahí que para su estudio se ha dividido en tres subsistemas: leche pasteurizada, leches industrializadas y derivados lácteos.

En la pasteurización se ha operado, en su mayor parte, con capital nacional privado. Se observa una tendencia al funcionamiento de grandes plantas con capacidad para pasteurizar elevados volúmenes de leche, que requieren de fuertes inversiones de capital y acopio de grandes cantidades de materia prima, a semejanza del modelo estadounidense, por lo que se requiere una integración vertical hacia la producción primaria.

Esta situación ha permitido una mayor concentración de la producción en un número menor de establecimientos. En 1970, alrededor de cuatro establecimientos procesan el $34.4 \%$ del total. En 1975 , los cinco establecimientos mayores produjeron $41.4 \%$ del total (cuadro 17) y hacia 1983, el $15 \%$ de los establecimientos procesaron el $67.5 \%$. Sin embargo, existen serios problemas de abasto de materia prima, ello obedece a que las plantas se ubican en las zonas cercanas al mercado del producto final, y no se cuenta con infraestructura adecuada para su traslado; así como a la baja rentabilidad que provoca el control de precios, con cllo se desalienta el desarrollo de esta actividad, por lo que se presenta una baja en la inversión por una parte, y por otra, se provoca una diversificación de productos como derivados lácteos, en los que opera un mercado libre. Las empresas pasteurizadoras operan a menos del $50 \%$ de su capacidad instalada y han reducido su actividad en la década, en cuanto a número de plantas, de 148 en 1970; a 116 en 1980 (cuadro 16); y hacia 1983, según información de la Coordinación de Agroindustria, había sólo 110 establecimientos (Uno más Uno, abril de 1983). Igualmente, aun cuando el volumen de pasteurización ha aumentado, su nivel de crecimiento es menor. En 1970 se procesaron 922.906 millones de litros; en $1975,1323.457$ millones de litros y en 1980 se alcanzó un volumen de 1529.417 millones de litros; lo que expresa un aumento de $43 \%$ en el primer quinquenio y de sólo $15 \%$ en el segundo. 5

En los EFN también se observa el mismo comportarniento; una disminución en el número de plantas, con excepción de Sonora, donde pasó de ocho establecimientos en 1970, a once en 1975 y a diez en 1980.

El volumen de leche pasteurizada en EFN se incrementó en Chihuahua, Nuevo León, Baja California y Sonora; mientras que en Coahuila y en Tamaulipas se observó, durante la década, una reducción del 37 y $39 \%$ respectivamente (cuadro No. 14a).

${ }^{5}$ Datos del SAM, INL, SARH. 
El proceso de pasteurización es relativamente sencillo, pero el equipo es automatizado y requiere de mantenimiento y cuidados sanitario especiales y estrictos. La maquinaria de pasteurización, así como la de envasado, son de importación en su totalidad. Es aquí, a través de la tecnología, en donde las empresas trasnacionales hacen acto de presencia.

Las leches industrializadas (condensada, evaporada y en polvo) presentan una enorme participación de empresas trasnacionales y un elevado nivel de concentración (cuadros 16 y 18 ).

Hasta 1984, la leche evaporada se producía por Carnation Company, pero esta empresa fue adquirida por Nestlé Alimentana; por lo que a partir de entonces esta última es la única productora de leche evaporada con azúcar y sin ella, mediante su filial Compañía Nestlé S.A. Domina todo el mercado de leche condensada y en cuanto a la evaporada, maquila para LiCONSA una cierta cantidad, que en 1983 era de aproximadamente $28 \%$ del total de su producción.

La fabricación de leche en polvo la llevan a cabo varias empresas, pero en ellas predomina la actividad de Nestlé con un $97 \%$ en obtención de leche en polvo entera y descremada; y un $59 \%$ en leche maternizada.

La tecnología empleada tiene un alto grado de automatización y sólo se vende a las filiales, por lo cual mantiene una dependencia tecnológica muy fuerte. La maquinaria se tiene que importar y el uso de patentes y marcas implica una permanente sangría para el país.

La forma como se relaciona con la producción primaria, parte de sus requerimientos de elevados volúmenes de materia prima; sin embargo, a diferencia de la pasteurización que requiere de cierto nivel de grasa, aqur la leche fluida puede ser de diferentes calidades y también se puede operar con leche rehidratada.

El abastecimiento de materia prima es a través de contratos verbales con pequeños productores. Las empresas proporcionan asesoría técnica y sirven de aval en los créditos. Por su parte, los productores comprometen sus ventas con la empresa. Además, consiguen leche en polvo de importación, obteniéndola a precio subsidiado, de manera que pueden trabajar empleando toda su capacidad.

El último subsistema, derivados lácteos (queso, cremia y mantequilla), es de las líneas que tiene un mayor dinamismo dentro de la rama; fundamentalmente, porque goza de un mercado libre de control de precios. 
Se trata de una actividad dinámica que ha aumentado su volumen de producción considerablemente. Los establecimientos son privados. A nivel comercial-industrial se ha dado un proceso de concentración muy importante: en 1975 siete establecimientos (1.9\% del total) procesaban $52.5 \%$, mientras que el $90 \%$ de los establecimientos contribuían al producto con $18 \%$ del total (cuadros $15 \mathrm{a}, \mathrm{b}, 16$ y 20 ).

Las principales empresas productoras de derivados lácteos son subsidiarias de empresas trasnacionales, sólo Noche Buena S.A. es de capital nacional.

La tecnología es diversa; encontramos desde la de tipo doméstico hasta la más avanzada. También se sostiene una dependencia tecnológica especialmente provocada por las técnicas empleadas en las empresas filiales de trasnacionales, a quienes se les paga por patentes y marcas, en tanto que la maquinaria se importa.

La vinculación con la producción primaria se presenta según el tipo de tecnología empleada y la escala de producción. La leche fluida puede adquirirse de las pequeñas y medianas explotaciones, y se tiene acceso también a leche rehidratada; esto en el caso de altos niveles de producción. En los establecimientos de tipo familiar, de hecho, pueden ser los mismos productores de leche fresca quienes, si no venden su producto de inmediato, lo dedican a la eláboración de quesos frescos y crema, lo que permite un período más amplio de conservación y posibilita venderlos en los mercados más cercanos.

\section{PRODUCCION PRIMARIA DE LECHE}

La ganadería lechera comienza a tener importancia en México hacia 1950. Su expansión se realiza apoyada en la política de fomento a la ganadería por parte del Estado y merced al desarrollo de agroindustrias que demandan materias primas. Esta situación ha ido acompañada de una modernización en la actividad que nos ocupa. En las últimas décadas se establecen explotaciones con ganado estabulado que consiguen mayor productividad y mejor calidad de producto. En este proceso se requierc alimentación para los semovientes, mejorada a base de concentrados, lo cual trae como consecuencia un desplazamiento de cultivos de subsistencia destinados a la alimentación humana, por cultivos forrajeros utilizados para el consumo animal. Sin embargo, no se trata de competencia entre el consumo humano y el consumo animal, porque en última instancia el animal se utiliza también para el consumo humano, sólo que este alimento va dirigido a los grupos de población de ingresos altos y medios, mientras que los cultivos que se dejan de obtener son alimentos dirigidos a núcleos de población de bajos ingresos. 
El hato lechero se había incrementado, aunque de manera discreta, hasta 1980; es a partir de 1981 en que se reduce de 5.5 a 5.2 millones de vacas, y todavía en 1983 ha mantenido la tendencia a la baja. El ganado especializado ha sido el más afectado; para este sector la disminución se inicia desde 1979 en que pasa de 1.03 a 0.90 millones de vacas hasta llegar a 1983 con sólo 0.88 millones de semovientes.

Actualmente, la ganadería lechera nacional está constituida por aproximadamente 5.1 millones de animales, de los cuales $17.4 \%$ se agrupan en el sistema de explotación especializada y el $82.6 \%$ en el de ganado no especializado. A los primeros corresponde un $54.3 \%$ de la producción, y a los segundos el $45.7 \%$ de una producción de 6.8 miles de millones de litros (cuadro 13). El ganado lechero ubicado en EFN representa aproximadamente el $20 \%$ del total y se ubica principalmente en Coahuila (Comarca Lagunera) Chihuahua, Baja California y Nuevo León (Cuadro 14a). Este grupo de entidades federativas corresponde a las características de región árida y semiárida, con excepción de Tamaulipas, que corresponde a la región tropical húmeda en la Huasteca, y seca en el resto.

En esa zona se han destinado áreas de riego para cultivos forrajeros y praderas artificiales, y también se aprovechan áreas de temporal para producir forrajes. Los esquilmos y subproductos agrícolas son igualmente aprovechados. Con estas características se desarrolla una ganadería lechera con elevados rendimientos, en coexistencia con una ganadería de libre pastoreo, en donde destaca la concen tración en la Comarca Lagunera.

Para un mayor acercamiento a la problemática de la producción primaria, se consideran dos elementos debido a su importancia en el comportamiento del sistema: las formas de explotación y las condiciones de tenencia de la tierra.

Las formas de explotación son de tipo intensivo, semiestabulada y de libre pastoreo y se diferencian en cuanto a organización, manejo, condiciones de sanidad animal y mejoramiento del hato lechero, según se incorporen adelantos tecnológicos que se expresan en la productividad del ganado. Generalmente, la tecnificación se detcrmina por la integración del productor primario a las siguientes fases del sistema, especialmente, a la de transformación.

La producción de tipo intensivo se refiere a la ganadería estabulada; cuenta con ganado especializado, maquinaria e instrumentos de producción, utiliza trabajo calificado y asistencia técnica para los productores; se trata de una organización de trabajo planeada que requiere de inversión elevada. Este sistema mantiene integración hacia adelante con la pasteurización fundamentalmente. 
Los costos de este sistema de explotación son los más altos porque requieren alimentacion a base de concentrados, ganado especializado, etc; es decir, se requiere importación de insumos. Sin embargo, es la más productiva en términos de rendimientos; la producción media anual por vaca, en 1983, fue de 4,138 litros en un período de lactancia de 210 a 305 días. Los más altos índices de rendimiento los encontramos en Baja California y Coahuila, en donde se obtuvieron 5139 y 5076 litros vaca-año (cuadro 13).

La explotación semiestabulada tiene un grado de tecnificación más limitado, opera con costos más bajos, pues si bien se aplican al ganado más avanzadas formas de mancjo y alimentación, la ordeña es fundamentalmente manual. El destino de su producto se dirige hacia el consumo directo como leche fresca (bronca), a producción semidoméstica de queso y crema, o bien se utiliza en la elaboración de productos industrializados. La producción media anual por vaca es de 644 litros, durante un período de lactancia que va de 120 a 150 días (cuadro 13).

La explotación de libre pastoreo tiene bajos niveles de rendimiento. Se trata de ganado de doble propósito, cuyo interés se orienta a la producción de carne; la leche se obtiene como actividad adicional y sus costos son los más bajos. La producción media anual por vaca es de 304 litros en un período de lactancia entre 50 y 150 días (cuadro No. 13). Se encuentra localizada en sitios de difícil acceso, por lo que se observa una mayor participación de intermediarios. Su utilización es básicamente para la industria. Resulta que el $82.6 \%$ del ganado lechero se maneja en forma desorganizada; sin recursos técnicos, y cuya ordeña es básicamente estacional.

En cuanto a las condiciones de la tenencia de la tierra, cabe anotar que la ganadería se ha desarrollado en mayor medida en unidades privadas, y en ellas se encuentra el ganado más eficiente, ${ }^{6}$ mientras que en ejidos, comunidades agrarias y pequeñas unidades productivas, prevalecen condiciones de pequeña explotación, atrasada y con baja productividad. El ganado especializado, se localiza en un $85.4 \%$, en unidades productivas privadas con más de 5 hectáreas, y el resto, en unidades hasta de 5 has y en comunidades agrarias.

El ganado no especializado se encuentra distribuido de la siguiente manera: $41.7 \%$ en unidades productivas privadas con más de 5 has, $13.5 \%$ en unidades hasta de 5 has, $26.7 \%$ en ejidos y comunidades agrarias, y $18.1 \%$ en poblaciones.

En estas condiciones se observa que se utilizan grandes extensiones de tierra en esta actividad, por lo que no se tiene un buen aprovechamiento de

6Con excepción del Complejo Industrial de Tizayuca, Hgo, que utiliza el mínimo espacio para el de. sempeño de su actividad y cuenta con ganado especializado. 
recursos, ya que buena parte de esta superficie podría incorporarse a la frontera agrícola.

Actualmente, la producción primaria de leche se encuentra en crisis. Su volumen creció hasta 1982 y para el siguiente año pasa de 6.9 a 6.7 miles de millones de litros. Además, su ritmo de crecimiento ha sido variable (cuadro 13).

Las razones de este comportamiento podemos encontrarlas en las bajas sufridas por el hato lechero, por la elevación del costo de mantenimiento y reposición, así como de los insumos, y por los cambios sufridos en la moneda nacional. En la producción primaria con ganado especializado, sc mantiene dependencia del exterior, especialmente, en ganado de reposición, semen, componentes de alimentos, maquinaria etc. por lo que los costos de producción se han incrementado considerablemente.

Conviene destacar que el rendimiento medio anual por vaca, en el caso del ganado especializado, conservó su ascenso hasta 1982, ya que en el último año estudiado la productividad decayó. El ganado no especializado presentó rendimientos variados en este período; sin embargo, en los últimos cuatro años mantuvo una tendencia a aumentar; de ahí pues el sostenimiento de la elevación moderada de la producción hasta 1982.

El gobierno ha fomentado la producción de leche con la creación de instituciones de apoyo y asistencia, facilidades en préstamos, creación de cuencas lecheras, instalación de plantas pasteurizadoras de CONASUPO, etc. Pero todas estas acciones carecen de una integración entre sí y son insuficientes. Además, en todo caso benefician a los grandes productores, porque son ellos quienes reúnen los requisitos para aprovechar esos apoyos.

Como puede observarse, la política agropecuaria ha propiciado un desarrollo desigual fortaleciendo a grupos reducidos de productores, en los que se concentraron el crédito y otros recursos tecnológicos por una parte, resultando en el deterioro de las condiciones económicas de amplios sectores de la población campesina.

\section{COMENTARIO}

De lo anteriormente expuesto, podemos desprender que toda la actividad desplegada mediante la modernización de la agroindustria para conseguir un mayor volumen de producción ha sido causa, y a la vez efecto, de una estructura productiva con marcadas tendencias hacia la concentración en cada uno de los subsistemas tratados; fincada sobre la base de la utilización de formas modernas de producción en grandes empresas que coexisten con formas tradicionales atrasadas que se emplean en pequeñas unidades productivas. Di- 
cha modernización contribuye a la mayor concentración porque requiere de una producción en gran escala, y por lo tanto, de una mayor inversión.

Ahora bien, por las características propias de un mercado en donde los precios de los productos básicos (leche pastcurizada) están sujetos a control por parte del Estado, el desarrollo de la industria se ha dirigido hacia la fabricación de productos no básicos, porque en ellos se obtiene una mayor rentabilidad, debido a que se ha generado demanda para ellos internamente: por el desarrollo urbano, por la incorporación masiva de la mujer al trabajo asalariado y por la seguridad del consumo del sector de la población de ingresos altos. Asimismo, el nivel de concentración conforma un mercado oligopólico que además funciona libre de control de precios por parte del Estado.

En la elaboración de leche pasteurizada se observa también la utilización de técnicas modernas, a la altura de países desarrollados, pero que dadas las características de nuestro país, no ha sido posible obtener un producto menos costoso. A pesar de que se mantiene un control sobre el precio, éste ha aumentado considerablemente. El deterioro del ingreso de amplios sectores de la población agrava aún más esta situación, de tal manera que cada vez tienen menos posibilidades de adquirir este producto.

Hay también, por otra parte, un serio problema de abastecimiento de materia prima. La producción primaria de leche presenta una estructura productiva polarizada. Los que operan con una mayor productividad y aportan más de la mitad de la producción, tienen un sistema dependiente del exterior en insumos, equipo y financiamiento. En cambio, los que operan con ganado estacional tienen una productividad muy baja. De modo que los primeros, enfrentan problemas de rentabilidad, y los segundos, realizan actividades de manera desorganizada en mancjo y sanidad; por lo tanto, la actividad pecuaria se encuentra trabajando de manera ineficiente. 


\section{INDICE DE CUADROS}

CUADRO 1. Producción nacional de leche de vaca.

CUADRO 2. Importaciones de leche en polvo.

CUADRO 3. Destino y utilización de la producción de Leche de vaca.

CUADRO 4. Destino de la leche en polvo importada.

CUADRO 5. Consumo percapita diario de productos lácteos, según estratos de ingreso.

CUADRO 6. Principales cuencas lecheras en el país.

CUADRO 7. Baja California: ganadería lechera, inventario y produccion CUADRO 8. Coahuila: ganadería lechera, inventario y producción.

CUADRO 9. Chihuahua: ganadería lechera, inventario y producción.

CUADRO 10. Nucvo León: ganadería lechera, inventario y producción

CUADRO 11. Sonora: ganadería lechera, inventario y producción

CUADRO 12. Tamaulipas: ganadería lechera, inventario y producción

CUADRO 13. Ganadería lechera nacional. Inventario y producción.

CUADRO 14a. Estados fronterizos del Norte: ganadería lechera. Inventario y producción 1983 .

CUADRO 14b. Estados fronterizos del Norte: sistema de explotación y entidad federativa. 1978.

CUADRO 15a. Producto interno bruto de la industria manufacturera de la industria de alimentos y de leche y derivados.

CUADRO 15b. Crecimiento de la producción bruta total de la industria de leche y productos lácteos.

CUADRO 16. Evolución del número de empresas.

CUADRO 17. Estructura de la industria de pasteurización rehidratación, homogeneización y embotellado de leche.

CUADRO 18. Empresas industrializados de leche en México.

CUADRO 19. Pasteurización en los estados fronterizos del Norte.

CUADRO 20. Fabricación de crema, mantequilla y queso en los estados fronterizos del Norte. 
CUADRO 1. Producción nacional de leche de vaca.

\begin{tabular}{ccc}
\hline ANO & $\begin{array}{c}\text { PRODUCCION DE LECHE } \\
\text { (MILLONES DE LITROS) }\end{array}$ & $\begin{array}{c}\text { INCREMENTO CON RELACION } \\
\text { AL ANO ANTERIOR \% }\end{array}$ \\
\hline 1970 & 4483.0 &.- \\
1971 & 4694.1 & 4.70 \\
1972 & 4915.2 & 4.71 \\
1973 & 5225.3 & 6.30 \\
1974 & 5500.0 & 5.25 \\
1975 & 5808.8 & 5.61 \\
1976 & 5907.3 & 1.69 \\
1977 & 6180.9 & 4.63 \\
1978 & 6509.4 & 5.31 \\
1979 & 6641.9 & 2.03 \\
1980 & 6741.5 & 1.49 \\
1981 & 6856.4 & 1.70 \\
1982 & 6923.6 & 0.98 \\
1983 & 6768.4 & -2.24 \\
\hline
\end{tabular}

FUENTE: Instituto Nacional de la leche 1980, citado por CODAI y Compendio histórico. Estad ístca del Subsector Pecuario 1972-1983. SARH.

CUADRO 2. Importaciones de leche en polvo: volumen, valor y precio.

\begin{tabular}{lcrr}
\hline ANOS & $\begin{array}{c}\text { VOLUMEN } \\
\text { (Toneladas) }\end{array}$ & $\begin{array}{r}\text { VALOR } \\
\text { (\$ miles) }\end{array}$ & $\begin{array}{r}\text { PRECIO POR } \\
\text { TONELADA }\end{array}$ \\
\hline 1970 & 36800 & 97488 & 2649.13 \\
1971 & 38400 & 229113 & 5966.48 \\
1972 & 39041 & 285675 & 7317.31 \\
1973 & 43483 & 535425 & 12313.43 \\
1974 & 96879 & 1138588 & 11752.68 \\
1975 & 14715 & 171625 & 11663.27 \\
1976 & 50694 & 265113 & 5229.67 \\
1977 & 77505 & 758076 & 9780.99 \\
1978 & 75893 & 830185 & 10938.89 \\
1979 & 78479 & 1015381 & 12938.25 \\
1980 & 80970 & n. d. & \\
1981 & 83400 & n. d. & \\
1982 & 85730 & n. d. & \\
1983 & 96820 & n. d. & \\
\hline
\end{tabular}

FUENTE: SARH Subsecretaría de Ganadería, INL.

(Elaborado con datos de la gerencia auxiliar de CONASUPO. Tomado de Sitjar Rousserie, Gabriel y Sergio Osorio Romero, Op. cit, y SARH,Compendio histórico, Estadísticas del subsector pecuario.

* Calculado con base en los datos de valor en tre el volumen. 
CUADRO 3.: Destino y utilización de la producción de leche de vaca (millones de litros).

\begin{tabular}{|c|c|c|c|c|c|c|c|c|}
\hline CONCEPTO & 1977 & $\%$ & 1978 & $\%$ & 1979 & $\%$ & 1980 & $\%$ \\
\hline INDUSTRIALIZACION & 1722.3 & 28.7 & 1802.1 & 27.7 & 1686.4 & 25.4 & 1748.2 & 25.0 \\
\hline 1. Leches industrializadas & 552.3 & 8.9 & 504.4 & 7.8 & 378.3 & 5.7 & 413.4 & 6.1 \\
\hline Evaporada & 33.8 & 0.5 & 46.9 & 0.7 & 16.6 & 0.3 & 15.8 & 0.2 \\
\hline Condensada & 139.1 & 2.2 & 110.1 & 1.8 & 102.5 & 1.5 & 118.3 & 1.8 \\
\hline En polvo, entera & 220.0 & 3.6 & 184.8 & 2.8 & 149.2 & 2.2 & 172.3 & 2.5 \\
\hline En polvo, descremada & 60.0 & 1.0 & 63.0 & 1.0 & 12.0 & 0.2 & 5.5 & 0.1 \\
\hline Dietética & 97.4 & 1.6 & 97.6 & 1.5 & 98.0 & 1.5 & 101.5 & 1.5 \\
\hline 2. Derivados lácteos & 1220.0 & 19.8 & 1293.7 & 19.9 & 1308.1 & 19.7 & 1334.8 & 19.8 \\
\hline Quesos & 795.0 & 12.9 & 842.9 & 12.9 & 852.0 & 12.8 & 861.2 & 12.8 \\
\hline Mantequillas & 248.8 & 4.0 & 264.0 & 4.1 & 267.1 & 4.0 & 279.9 & 4,0 \\
\hline Cremas & 123.0 & 2.0 & 129.9 & 2.0 & 130.6 & 2.0 & 139.6 & 2.1 \\
\hline Otros & 54.0 & 0.9 & 56.9 & 0.9 & 58.4 & 0.9 & 61.1 & 0.9 \\
\hline PASTEURIZACION & 1454.6 & 23.5 & 1542.8 & 23.7 & 1535.1 & 23.1 & 1507.1 & 22.4 \\
\hline LECHE BRONCA & 2954.0 & 47.8 & 3164.7 & 48.6 & 3420.4 & 51.5 & 3486.2 & 51.7 \\
\hline TOTAL & 6180.0 & 100.0 & 6509.6 & 100.0 & 6641.9 & 100.0 & 6741.5 & 100.0 \\
\hline
\end{tabular}

FUENTE: Instituto Nacional de L leche SARH. 
CUADRO 4.: Destino de leche en polvo importada por CONASUPO. 1978.

\begin{tabular}{lrr}
\hline \multicolumn{1}{r}{ EMPRESA } & VOLUMEN & $\%$ \\
\hline LICONSA & $26,070.2$ & 43 \\
DIF & $3,031.4$ & 5 \\
TRICONSA & $1,212.8$ & 2 \\
CARNATION & $16,369.6$ & 27 \\
NESTLE & $6,669.1$ & 11 \\
OTRAS & $7,275.2$ & 12 \\
\hline
\end{tabular}

FUENTE: Secretaría del Patrimonio y Fomento industrial, Datos presentados por el SAM.

CUADRO 5. Consumo per cápita diario de productos lácteos según estratos de ingreso (gramos).

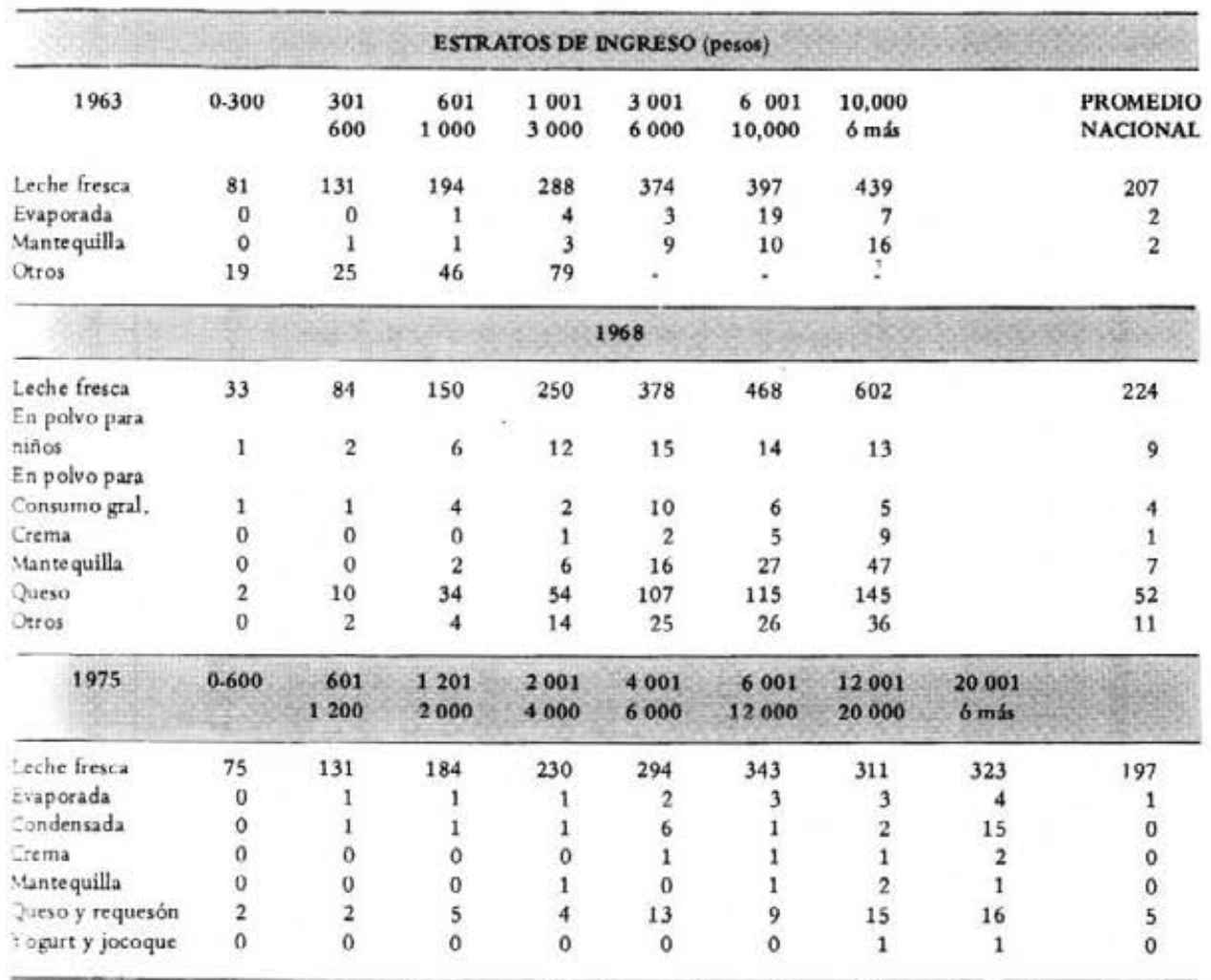

SLENTE; Elaborado por PROCAP con datos oficiales de las encuestas de ingeso y gastos de las familias $1963,19,8$ y 1975 . 
CUADRO 6. Principales cuencas lecheras en el pars. 1977.

\begin{tabular}{lccc}
\hline \multicolumn{1}{|c}{ CUENCAS Y LOCALIzACIONES } & $\begin{array}{c}\text { GANADERIA } \\
\text { LECHERA }\end{array}$ & $\begin{array}{c}\text { PRODUCCION DE } \\
\text { LECHE }\end{array}$ & $\begin{array}{c}\text { RENDIMIENTO ANUAL } \\
\text { POR VACA }\end{array}$ \\
\hline & (Cabezas) & $\begin{array}{c}\text { Millones de } \\
\text { litros }\end{array}$ & Litros \\
Pabellón, Aguascalientes y Rincón de & & & \\
Romos, Ags. & 22206 & 64.9 & 2923.4 \\
$\begin{array}{l}\text { Comarca Lagunera (Dgo., Coah.) } \\
\text { Delicias, Jiménez, Cuauhtémoc, Chi- }\end{array}$ & 88200 & 362.1 & 4105.4 \\
huahua (Chih.) & 46100 & 159.6 & 3462.0 \\
$\begin{array}{l}\text { Silao, León, Celaya (Gto.) } \\
\text { Tulancingo, Pachuca, Ixmiquilpan }\end{array}$ & 50025 & 98.5 & 1970.0 \\
$\begin{array}{l}\text { Tizayuca (Hgo.) } \\
\text { Los Altos, Ciénega de Chapala, (Jal.) }\end{array}$ & 27200 & 72.6 & 2669.1 \\
$\begin{array}{l}\text { Cuautitlán, Texcoco, Chalco, Tenan- } \\
\text { go.Toluca (México) }\end{array}$ & 148700 & 357.4 & 2403.5 \\
$\begin{array}{l}\text { San Juan del Río, Colón, Querétaro, } \\
\text { Villa del Marquez (Qro.) }\end{array}$ & 39740 & 326.1 & 2630.3 \\
$\begin{array}{l}\text { Zona Norte, Jalapa, Córdoba, Orizaba } \\
\text { y los Tuxtlas (Ver) }\end{array}$ & 175300 & 103.6 & 2607.0 \\
Atlixco, Chipilo, Cholula, Tehuacán, & 53100 & 312.4 & 1782.1 \\
San Martín (Pue.) & 107.8 & 2030.9 \\
\hline
\end{tabular}

FUENTE; INL (estimaciones), Coordinación Gral. de Desarrollo Agroindustrial, SARH. 
CUADRO 7. Baja California: ganadería lechera, inventario y producción. 1972-1983.

\begin{tabular}{|c|c|c|c|c|c|c|c|c|c|}
\hline \multicolumn{4}{|c|}{ GANADERIA ESPECIALIZADA ${ }^{1}$} & \multicolumn{3}{|c|}{ NO ESPECIALIZADA² } & \multicolumn{3}{|c|}{ TOTAL } \\
\hline Años & Inventario & $\begin{array}{c}\text { Rendimientos } \\
\text { (litros) }\end{array}$ & $\begin{array}{l}\text { Producción } \\
\text { (miles de } \\
\text { litros) }\end{array}$ & Inventario & $\begin{array}{l}\text { Rendimientos } 3 \\
\quad \text { (litros) }\end{array}$ & $\begin{array}{l}\text { Producción } \\
\text { (miles de } \\
\text { litros) }\end{array}$ & Inventario & $\begin{array}{l}\text { Rendimien tos } 3 \\
\text { (litros) }\end{array}$ & $\begin{array}{c}\text { Producción } \\
\text { (miles de } \\
\text { litros) }\end{array}$ \\
\hline 1972 & 14,633 & 2,834 & 41,470 & 18,792 & 762 & 14,327 & 33,425 & 1,669 & 55,797 \\
\hline 1973 & 15,741 & 2,997 & 47,176 & 20,076 & 782 & 15,699 & 35,817 & 1,755 & 62,875 \\
\hline 1974 & 18,150 & 3,153 & 57,224 & 21,033 & 782 & 16,448 & 39,183 & 1,880 & 73,672 \\
\hline 1975 & 18,796 & 3,296 & 61,950 & 22,115 & 781 & 17,277 & 40,911 & 1,937 & 79.227 \\
\hline 1976 & 18,832 & 3,394 & 63,921 & 23,013 & 737 & 16,950 & 41,845 & 1,933 & 80,871 \\
\hline 1977 & 19,304 & 3,464 & 66,870 & 25,020 & 790 & 19,766 & 44,324 & 1,955 . & 86,636 \\
\hline 1978 & 19,850 & 3,689 & 73,218 & 26,174 & 804 & 21,033 & 46,024 & 2,048 & 94,251 \\
\hline 1979 & 21,074 & 4,275 & 90,091 & 27,072 & 963 & 26,076 & 48,146 & 2,413 & 116,167 \\
\hline 1980 & 22,235 & 4,624 & 102,815 & 27,745 & 726 & 20,143 & 49,980 & 2,460 & 122,958 \\
\hline 1981 & 20,114 & 5,027 & 101,113 & 10,506 & 2,980 & 31,307 & 30,620 & 4,325 & 132,420 \\
\hline 1982 & 20,131 & 5,137 & 103,411 & 11,489 & 2,856 & 32,814 & 31,620 & 4,308 & 136,225 \\
\hline 1983 & 18,215 & 5,139 & 93,607 & 10,963 & 2,860 & 31,354 & 29,178 & 4,282 & 124,961 \\
\hline
\end{tabular}

1 Se considera a todos los vientres cuya función zootécnica está orientad a la producción de leche.

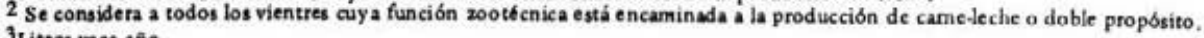

FUENTE: SARH, Compendio histórico, Estadísticas del subsector pecuario, 
CUADRO 8. Coahuila: ganaderfa lechera, inventario y producción. 1972-1983.

\begin{tabular}{|c|c|c|c|c|c|c|c|c|c|}
\hline \multicolumn{4}{|c|}{ a. GANADERIA ESPECIALIZADA 1} & \multicolumn{3}{|c|}{ b. NO ESPECIALIZADA² } & \multicolumn{3}{|c|}{ c. TOTAL } \\
\hline Años & Inventario & $\begin{array}{l}\text { Rendimientos } 3 \\
\text { (litros) }\end{array}$ & $\begin{array}{c}\text { Produceibn } \\
\text { (miles de } \\
\text { liuros) }\end{array}$ & Inventario & $\begin{array}{c}\text { Rendimientos }{ }^{3} \\
\text { (litros) }\end{array}$ & $\begin{array}{c}\text { Producción } \\
\text { (miles de } \\
\text { litros) }\end{array}$ & Inventario & $\begin{array}{c}\text { Rendimientos } \\
\text { (litros) }\end{array}$ & $\begin{array}{c}\text { Produccibn } \\
\text { (miles de } \\
\text { litros) }\end{array}$ \\
\hline $\begin{array}{l}1972 \\
1973 \\
1974 \\
1975 \\
1976 \\
1977 \\
1978 \\
1979 \\
1980 \\
1981 \\
1982 \\
1983\end{array}$ & $\begin{array}{l}57,807 \\
63,294 \\
71,177 \\
71,686 \\
71,847 \\
73,647 \\
75,734 \\
67,039 \\
66,112 \\
67,901 \\
67,370 \\
63,631\end{array}$ & $\begin{array}{l}3,905 \\
4,064 \\
4,240 \\
4,240 \\
4,287 \\
4,375 \\
4,569 \\
4,934 \\
5,401 \\
5,041 \\
5,077 \\
5,076\end{array}$ & $\begin{array}{l}225,736 \\
257,227 \\
301,815 \\
303,933 \\
308,017 \\
322,226 \\
346,046 \\
330,770 \\
343,353 \\
342,764 \\
342,016 \\
322,991\end{array}$ & $\begin{array}{r}91,164 \\
94,338 \\
94,904 \\
97,029 \\
97,869 \\
101,838 \\
106,032 \\
106,602 \\
104,400 \\
87,912 \\
81,948 \\
79,853\end{array}$ & $\begin{array}{l}692 \\
694 \\
693 \\
695 \\
700 \\
805 \\
818 \\
879 \\
722 \\
717 \\
715 \\
724\end{array}$ & $\begin{array}{l}63,071 \\
65,471 \\
65,768 \\
67,435 \\
68,508 \\
81,980 \\
86,738 \\
93,669 \\
75,377 \\
62,998 \\
58,613 \\
57,834\end{array}$ & $\begin{array}{l}148,971 \\
157,632 \\
166,081 \\
168,715 \\
169,716 \\
175,485 \\
181,766 \\
173,641 \\
172,512 \\
155,813 \\
149,318 \\
143,484\end{array}$ & $\begin{array}{l}1,939 \\
2,047 \\
2,213 \\
2,201 \\
2,219 \\
2,303 \\
2,381 \\
2,444 \\
2,427 \\
2,604 \\
2,683 \\
2,654\end{array}$ & $\begin{array}{l}288,807 \\
322,698 \\
367,583 \\
371,368 \\
376,525 \\
404,206 \\
432,784 \\
424,439 \\
418,730 \\
405,762 \\
400,629 \\
380,825\end{array}$ \\
\hline
\end{tabular}

ISe conaidera a todos los vientres cuya funeión zootécniea estí orientada a la producción de leche.

${ }^{2}$ Se condidera a todos los vientres euya función zootienies estí encaminada a la producción de carnedeche o doble propósito.

${ }^{3}$ Litroo reca eñก).

FURNTE: SARH, Compendio histórico. Estadítices del subsector pecuario. 
CUADRO 9. Chihuahua ganaderfa lechera, inventario y producción. 1972-1983.

\begin{tabular}{|c|c|c|c|c|c|c|c|c|c|}
\hline \multicolumn{4}{|c|}{ A, GANADERIA ESPECIALIZADA1 } & \multicolumn{3}{|c|}{ b. NO ESPECIALIZADA 2} & \multicolumn{3}{|c|}{ c. TOTAL } \\
\hline Años & Inventario & $\begin{array}{l}\text { Rendimientos }{ }^{3} \\
\text { (litros) }\end{array}$ & $\begin{array}{l}\text { Producción } \\
\text { (miles de } \\
\text { litros) }\end{array}$ & Inven cario & $\begin{array}{l}\text { Rendimientos } 3 \\
\text { (litros) }\end{array}$ & $\begin{array}{c}\text { Produccion } \\
\text { (miles de } \\
\text { litros) }\end{array}$ & Inven tario & $\begin{array}{c}\text { Rendimientos. } \\
\text { (litros) }\end{array}$ & $\begin{array}{c}\text { Produccion } \\
\text { (miles de } \\
\text { litros) }\end{array}$ \\
\hline 1972 & 45,211 & 3,663 & 165,608 & 311,156 & 410 & 127,577 & 356,367 & 823 & 293,185 \\
\hline 1973 & 46,450 & 3,813 & 177,114 & 323,707 & 328 & 106,062 & 370,157 & 765 & 283,176 \\
\hline 1974 & 47,420 & 3,915 & 185,660 & 325,237 & 476 & 154,691 & 372,657 & 913 & 340,351 \\
\hline 1975 & 47,965 & 3,920 & 188,022 & 332,281 & 476 & 158,169 & 380,246 & 910 & 346,191 \\
\hline 1976 & 48,005 & 3,923 & 188,301 & 334,412 & 475 & 158,852 & 382,417 & 908 & 347,153 \\
\hline 1977 & 49,208 & 4,003 & 196,988 & 347,825 & 478 & 166,304 & 397,033 & 915 & 363,292 \\
\hline 1978 & 50,602 & 3,906 & 197,658 & 361,866 & 509 & 184,059 & 412,468 & 925 & 381,717 \\
\hline 1979 & 39,010 & 4,248 & 165,714 & 352,616 & 544 & 191,823 & 391,626 & 913 & 357,537 \\
\hline 1980 & 44,373 & 4,581 & 203,273 & 348,868 & 512 & 178,510 & 393,241 & 971 & 381.783 \\
\hline 1981 & 42,518 & 4,630 & 196,858 & 304,657 & 599 & 182,456 & 347,175 & 1,093 & 379,314 \\
\hline 1982 & 41,790 & 4,565 & 190,787 & 299,232 & 627 & 187,616 & 341,022 & 1,110 & 378,403 \\
\hline 1983 & 39,813 & 4,567 & 181,808 & 292,812 & 638 & 186,886 & 332,625 & 1,118 & 368,694 \\
\hline
\end{tabular}

${ }_{1}^{1}$ Se considera a todos los vientres cuya función zontécnica está orientada a la producción de lecie.

${ }^{2} \mathrm{Se}$ considera a todos los vientres cuya función zootécnica está encaminada a la producción de carne-deche o dohle propósito.

${ }^{3}$ Litros vaca-año.

FUENTE: SARH. Compendio histórico. Estadisticas del subsector pecuano. 
CUADRO 10. Nuevo León: ganadería lechera, inventario y producción. 1972-1983.

\begin{tabular}{|c|c|c|c|c|c|c|c|c|c|}
\hline \multicolumn{4}{|c|}{ 2. GANADERIA ESPECIALIZADA 1} & \multicolumn{3}{|c|}{ b. NO ESPECIALIZADA2 } & \multicolumn{3}{|c|}{ c. TOTAL } \\
\hline Años & Inventario & $\begin{array}{c}\text { Rendimientos } \\
\text { (litros) }\end{array}$ & $\begin{array}{c}\text { Producción } \\
\text { (miles de } \\
\text { litros) }\end{array}$ & Inventario & $\begin{array}{c}\text { Rendimientos } 3 \\
\text { (litros) }\end{array}$ & $\begin{array}{l}\text { Producción } \\
\text { (miles de } \\
\text { litros) }\end{array}$ & Inventario & $\begin{array}{c}\text { Rendimientos } 3 \\
\text { (litros) }\end{array}$ & $\begin{array}{l}\text { Producción } \\
\text { (miles de } \\
\text { litros) }\end{array}$ \\
\hline 1972 & 24,234 & 2,300 & 55,738 & 32,453 & 321 & 10,404 & 56,687 & 1,167 & 66,142 \\
\hline 1973 & 24,452 & 2,432 & 59,467 & 34,557 & 332 & 11,471 & 59,009 & 1.202 & 70,938 \\
\hline 1974 & 24,320 & 2,658 & 64,645 & 34,034 & 303 & 10,312 & 58,354 & 1,285 & 74,957 \\
\hline 1975 & 24,629 & 2,635 & 64,891 & 36,307 & 302 & 10,965 & 60,936 & 1,245 & 75,856 \\
\hline 1976 & 24,666 & 2,645 & 65,233 & 34,451 & 304 & 10,473 & 59,117 & 1,281 & 75,706 \\
\hline 1977 & 25,284 & 2,699 & 68,242 & 36,916 & 310 & 11,440 & 62,200 & 1,281 & 79,682 \\
\hline 1978 & 26,000 & 2,674 & 69,515 & 38,023 & 332 & 12,639 & 64,023 & 1,283 & 82,154 \\
\hline 1979 & 26,629 & 2,652 & 70,620 & 31,365 & 391 & 12,255 & 57,994 & 1,429 & 82,875 \\
\hline 1980 & 15,310 & 2,684 & 41,092 & 32,244 & 367 & 11,833 & 47,554 & 1,113 & 52,925 \\
\hline 1981 & 13,129 & 2,670 & 35,054 & 25,223 & 664 & 16,737 & 38,352 & 1,350 & 51,791 \\
\hline 1982 & 13,126 & 2,713 & 35,613 & 26,089 & 740 & 19,313 & 39,215 & 1,401 & 54,926 \\
\hline 1983 & 12,614 & 2,721 & 34,322 & 25,213 & 742 & 18,708 & 37,827 & 1,402 & 53,030 \\
\hline
\end{tabular}

${ }^{1}$ Se considera a todos los vientres cuya función zootecnica estí orien tada a la producción de leche.

${ }^{2} \mathrm{Se}$ considera a todos los vientres cuya función zootecnica está encaminada a la produc ción de carne-leche o doble propósito.

${ }^{3}$ Litron vaca-eño.

FUENTE: SARH, Compendio historico. Estadisticas del subsector pecuario. 
CUADRO 11. Sonora: ganadeŕa lechera, inventario y producción. 1972-1983.

\begin{tabular}{|c|c|c|c|c|c|c|c|c|c|}
\hline \multicolumn{4}{|c|}{ a. GANADERIA ESPECIALIZADAI } & \multicolumn{3}{|c|}{ b. NO ESPECIALIZADA2 } & \multicolumn{3}{|c|}{ c. TOTAL } \\
\hline Años & Inventario & $\begin{array}{c}\text { Rendimientos } \\
\text { (littos) }\end{array}$ & $\begin{array}{c}\text { Producción } \\
\text { (miles de } \\
\text { litros) }\end{array}$ & Inventario & $\begin{array}{c}\text { Rendimientos }{ }^{3} \\
\text { (litros) }\end{array}$ & $\begin{array}{l}\text { Producción } \\
\text { (miles de } \\
\text { litros) }\end{array}$ & Inventario & $\begin{array}{c}\text { Rendimientos } 3 \\
\text { (litros) }\end{array}$ & $\begin{array}{c}\text { Producción } \\
\text { (miles de } \\
\text { litros) }\end{array}$ \\
\hline 1972 & 10,112 & 2,304 & 23,298 & 143,638 & 520 & 74,714 & 153,750 & 637 & 98,012 \\
\hline 1973 & 10,309 & 2,442 & 25,175 & 151,149 & 531 & 80.260 & 161,458 & 653 & 105,435 \\
\hline 1974 & 11,145 & 2,612 & 29,107 & 154,061 & 528 & 81,347 & 165,206 & 669 & 110,454 \\
\hline 1975 & 11,171 & 2,615 & 29,217 & 157,077 & 540 & 84,822 & 168,248 & 678 & 114,039 \\
\hline 1976 & 10,989 & 2,674 & 29,382 & 150,962 & 542 & 81,821 & 161,951 & 687 & 111,203 \\
\hline 1977 & 11,264 & 2,729 & 30,737 & 169,679 & 537 & 91,136 & 180,943 & 674 & 121,873 \\
\hline 1978 & 11,583 & 2,682 & 31,066 & 164,541 & 561 & 92,278 & 176,124 & 700 & 123,344 \\
\hline 1979 & 13,794 & 3,337 & 46,031 & 153,985 & 635 & 97,750 & 167,779 & 857 & 143,781 \\
\hline 1980 & 13,527 & 3,692 & 49,942 & 147,428 & 588 & 86,688 & 160,955 & 849 & 136,630 \\
\hline 1981 & 13,960 & 3,762 & 52,518 & 133,870 & 655 & 87,631 & 147,830 & 948 & 140,149 \\
\hline 1982 & 13,951 & 3,763 & 52,501 & 137,155 & 661 & 90,707 & 151,106 & 948 & 143,208 \\
\hline 1983 & 13,948 & 3,765 & 52,514 & 133,287 & 670 & 89,236 & 147,235 & 962 & 141,750 \\
\hline
\end{tabular}

${ }_{1}^{1}$ Se considera a todos los vientres cuya función zootécnica está orientada a la producción de leche.

Se considera a todos los vientres cuya función zootécenica está enicaminada a la producción de carne-Jeche o doble proposito.

FUENTE: SARH, Compendio hist Orico. Estadisticas del subsector pecuario. 
CUADRO 12. Tamaulipas: ganadería lechera, inventario y producción. 1972-1983.

\begin{tabular}{|c|c|c|c|c|c|c|c|c|c|}
\hline \multicolumn{4}{|c|}{ a GANADERIA ESPECIAUIZADA1 } & \multicolumn{3}{|c|}{ b. NO ESPECIALIZADA2 } & \multicolumn{3}{|c|}{ c. TOTAL } \\
\hline Años & Inventario & $\begin{array}{c}\text { Rendimientos } \\
\text { (litros) }\end{array}$ & $\begin{array}{c}\text { Producción } \\
\text { (miles de } \\
\text { litros) }\end{array}$ & Inventario & $\begin{array}{c}\text { Rendimientos }{ }^{3} \\
\text { (litros) }\end{array}$ & $\begin{array}{l}\text { Producción } \\
\text { (miles de } \\
\text { lituos) }\end{array}$ & Inventario & $\begin{array}{c}\text { Rendimientos } 3 \\
\text { (litros) }\end{array}$ & $\begin{array}{l}\text { Producción } \\
\text { (miles de } \\
\text { lituos) }\end{array}$ \\
\hline 1972 & 5,397 & 1,743 & 9,407 & 140,212 & 358 & 50,159 & 145.609 & 409 & 59,566 \\
\hline 1973 & 5,173 & 1,898 & 9,818 & 146,360 & 362 & 52,982 & 151,533 & 414 & 62,800 \\
\hline 1974 & 5,271 & 2,053 & 10,821 & 150,005 & 354 & 53,052 & 155,276 & 411 & 63,873 \\
\hline 1975 & 5,295 & 2,078 & 11,004 & 153,994 & 365 & 56,208 & 159,289 & 422 & 67,212 \\
\hline 1976 & 5,304 & 2,078 & 11,024 & 153,558 & 367 & 56,357 & 158,862 & 424 & 67,381 \\
\hline 1977 & 5,437 & 2,121 & 11,533 & 170,933 & 368 & 62,955 & 176,370 & 422 & 74,488 \\
\hline 1978 & 5,591 & 2,100 & 11,741 & 171,118 & 384 & 65,645 & 176,709 & 438 & 77,386 \\
\hline 1979 & 5,726 & 2,110 & 12,082 & 225,137 & 400 & 90,022 & 230,863 & 442 & 102,104 \\
\hline 1980 & 6,391 & 2,108 & 13,472 & 223,944 & 487 & 109,061 & 230,335 & 532 & 122,533 \\
\hline 1981 & 6,433 & 2,209 & 14,210 & 195,679 & 557 & 109,032 & 202,112 & 610 & 123,242 \\
\hline 1982 & 6,420 & 2,898 & 18,604 & 201,071 & 551 & 110,820 & 207,491 & 624 & 129,424 \\
\hline 1983 & 6,403 & 2,916 & 18,669 & 197,378 & 559 & 110,255 & 203,781 & 633 & 128,924 \\
\hline
\end{tabular}

${ }_{1}^{1}$ Se considera a todos los vientres cuya función zootécnica cstí orientada a la producción de leche.

2Se considera a todos los vientres cuya función zootécnica está enéteninada a la producción de carne-Jeche o doble propónito.

FUENTE: SARH, Compendio historico, Estadísticas del subsector pecuario. 
CUADRO 13. Ganadería lechera nacional, inventario y producción. 1972-1983.

\begin{tabular}{|c|c|c|c|c|c|c|c|c|c|}
\hline \multicolumn{4}{|c|}{ a. GANADERIA ESPECIALZADAI } & \multicolumn{3}{|c|}{ b. NO ESPECIALIZADA ${ }^{2}$} & \multicolumn{3}{|c|}{ c. TOTAL } \\
\hline Años & Inventario & $\begin{array}{c}\text { Rendimientos } 3 \\
\text { (litros) }\end{array}$ & $\begin{array}{c}\text { Producción } \\
\text { (miles de } \\
\text { litros) }\end{array}$ & Inventario & $\begin{array}{c}\text { Rendimientos }{ }^{3} \\
\text { (litros) }\end{array}$ & $\begin{array}{l}\text { Producción } \\
\text { (miles de } \\
\text { litros) }\end{array}$ & Inventario & $\begin{array}{c}\text { Rendimientos } 3 \\
\text { (litros) }\end{array}$ & $\begin{array}{l}\text { Producción } \\
\text { (miles de } \\
\text { lituros) }\end{array}$ \\
\hline 1972 & 894,668 & 3,076 & $2,751,979$ & $3,754,843$ & 576 & $2,163,220$ & $4,649,511$ & 1,057 & $4,915,199$ \\
\hline 1973 & 920,630 & 3,208 & $2,953,400$ & $3,906,094$ & 582 & $2,271,944$ & $4,826,724$ & 1,083 & $5,225,344$ \\
\hline 1974 & 951,119 & 3,365 & $3,200,857$ & $3,999,951$ & 587 & $2,349,579$ & $4,951,070$ & 1,121 & $5,550,436$ \\
\hline 1975 & 980,408 & 3,448 & $3,380,567$ & $4,090,926$ & 594 & $2,428,221$ & $5,071,334$ & 1,145 & $5,808,788$ \\
\hline 1976 & 984,650 & 3,500 & $3,445,902$ & $4,165,227$ & 590 & $2,461,446$ & $5,149,877$ & 1,147 & $5,907,348$ \\
\hline 1977 & $1,009,300$ & 3,572 & $3,604,865$ & $4,392,019$ & 587 & $2,576,081$ & $5,401.319$ & 1,144 & $6,180,946$ \\
\hline 1978 & $1,037,893$ & 3,637 & $3,775,257$ & $4,497,018$ & 608 & $2,734,342$ & $5,534,911$ & 1,176 & $6,509,599$ \\
\hline 1979 & 909,334 & 3,902 & $3,548,553$ & $4,616,027$ & 670 & $3,093,350$ & $5,525,361$ & 1,202 & $6,641,903$ \\
\hline 1980 & 923,236 & 4,077 & $3,764,225$ & $4,624,050$ & 644 & $2,977,319$ & $5,547,286$ & 1,215 & $6,741,544$ \\
\hline 1981 & 915,320 & 4,143 & $3,792,311$ & $4,271,099$ & 717 & $3,064,104$ & $5,186,419$ & 1,322 & $6,856,415$ \\
\hline 1982 & 911,368 & 4,148 & $3,780,562$ & $4,335,282$ & 725 & $3,143,046$ & $5,246,650$ & 1,320 & $6,923,608$ \\
\hline 1983 & 888,362 & 4,138 & $3,675,821$ & $4,212,490$ & 734 & $3,092,581$ & $5,100,852$ & 1,327 & $6,768,402$ \\
\hline
\end{tabular}

1 Se considera a todos los vientres cuya función zootécnica está urientada a la producción de leche.

${ }_{2}^{2}$ e considera a todos los vientres cuya función zootéenica está encaminada a la producción de carne-leche o doble propósito.

${ }^{3}$ Litros vaca-año.

FUENTE: SARH, Compendio histórica. Estadísticas del subsector pecuario. 
CUADRO 14. Estados fronterizos del Norte: ganadería lechera, inventario y producción. 1983.

\begin{tabular}{|c|c|c|c|c|c|c|c|c|c|}
\hline & \multicolumn{3}{|c|}{ a. GANADERIA ESPECIALIZADA' } & \multicolumn{3}{|c|}{ b. NO ESPECIALIZADA2 } & \multicolumn{3}{|c|}{ c. TOTAL. } \\
\hline & Inventario & $\begin{array}{c}\text { Rendimientos } \\
\text { (litros) }\end{array}$ & $\begin{array}{l}\text { Producción } \\
\text { (miles de } \\
\text { litros) }\end{array}$ & Inventario & $\begin{array}{c}\text { Rendimientos }{ }^{3} \\
\text { (titros) }\end{array}$ & $\begin{array}{l}\text { Producción } \\
\text { (miles de } \\
\text { litros) }\end{array}$ & Inventario & $\begin{array}{l}\text { Rendimientos } \\
\text { (litros) }\end{array}$ & $\begin{array}{l}\text { Producción } \\
\text { (miles de } \\
\text { litros) }\end{array}$ \\
\hline Baja California & 18,215 & 5.139 & 93,607 & 10.963 & 2,860 & 31,354 & 29,178 & 4,282 & 124,961 \\
\hline Coahuila & 63,631 & 5,076 & 322,991 & 79,853 & 724 & 57,834 & 143,484 & 2,654 & 380,825 \\
\hline Chihuahua & 39,813 & 4,567 & 181,808 & 292,812 & 638 & 186,886 & 332,625 & 1,108 & 368,694 \\
\hline Nuevo León & 12,614 & 2.721 & 34.322 & 25.213 & 742 & 18,708 & 37,827 & 1,402 & 53,030 \\
\hline Sonora & 13,948 & 3,765 & 52,514 & 133,287 & 670 & 89,236 & 147,235 & 962 & 141,750 \\
\hline Tamaulipas & 6,403 & 2,916 & 18,669 & 197.378 & 559 & 110,225 & 203,781 & 633 & 128,924 \\
\hline \multicolumn{10}{|c|}{ Estados Fronterizos } \\
\hline del Nortc. & 154,624 & - & 703.911 & 739.506 & $\therefore$ & 494,243 & 894,130 & - & $1,198,184$ \\
\hline Total nacional & 888,362 & 4,138 & $3,675.821$ & $4,212.490$ & 734 & $3,092,581$ & $5,100,852$ & 1,327 & $6,768,402$ \\
\hline EFN/TOTAL & $17.4 \%$ & & $19.2 \%$ & $17.6 \%$ & - & $16.0 \%$ & $17.5 \%$ & - & $17.7 \%$ \\
\hline
\end{tabular}

1Se considera a todus los vientres cuy a función zootéenica está orien ada a L producción de leclur.

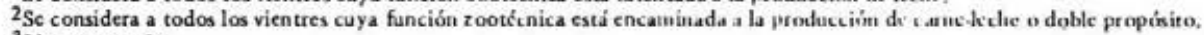

${ }^{3}$ Litros vaca-ano.

FUFNTE: SARH, Compendio histórico. Estadisticas del subecctor pecuario, 1972 198.1. 
CUADRO 14 b. Ganadería lechera. Estados fronterizos del Norte. Sistema de Explotación y entidad federativa. 1978.

\begin{tabular}{|c|c|c|c|c|c|c|c|c|c|c|c|c|}
\hline \multirow[b]{2}{*}{ Entidad federativa } & \multicolumn{3}{|c|}{ SISTEMA ESTABULADO } & \multicolumn{3}{|c|}{ SEMIESTABULADO } & \multicolumn{3}{|c|}{ LIBRE PASTOREO } & \multicolumn{3}{|c|}{ TOTAL } \\
\hline & N. vientres & $\begin{array}{l}\text { Producción } \\
\text { (miles } \\
\text { litros) }\end{array}$ & $\begin{array}{c}\text { Productividad } \\
\text { (litros) }\end{array}$ & N. vientres & $\begin{array}{l}\text { Producción } \\
\text { (miles } \\
\text { litros) }\end{array}$ & $\begin{array}{l}\text { Productividad } \\
\text { (litros) }\end{array}$ & N. vientres & $\begin{array}{l}\text { Producción } \\
\text { (miles } \\
\text { litros) }\end{array}$ & $\begin{array}{l}\text { Productividad } \\
\text { (litros) }\end{array}$ & N.vientres & $\begin{array}{l}\text { Producción } \\
\text { (miles } \\
\text { litros) }\end{array}$ & $\begin{array}{c}\text { Productividad } \\
\text { (lituos) }\end{array}$ \\
\hline Baja California & 19850 & 73218 & 3689 & 8773 & 6423 & 732 & 78811 & 24127 & 306 & 107434 & 103768 & 466 \\
\hline Coahuila & 75734 & 346046 & 4569 & 67437 & 40034 & 594 & 268022 & 74496 & 278 & 411193 & 470576 & 1120 \\
\hline Chihuahua & 50602 & 197658 & 3906 & 99967 & 64055 & 641 & 383436 & 92287 & 241 & 534055 & 354000 & 663 \\
\hline Nuevo León & 26000 & 69515 & 2674 & 11760 & 5691 & 484 & 30475 & 6217 & 204 & 68245 & 81923 & 1193 \\
\hline Sonora & 11583 & 31066 & 2682 & 21292 & 12393 & 579 & 59821 & 13211 & 221 & 92696 & 56000 & 611 \\
\hline $\begin{array}{l}\text { Tamaulipas } \\
\text { Estados fronterizos }\end{array}$ & 5591 & 11741 & 2100 & 97044 & 57191 & 589 & 354721 & 49461 & 139 & 457356 & 118400 & 259 \\
\hline del norte. & 189360 & 729244 & -. & 306273 & 185717 & . & 1175286 & 259799 & . & 1670912 & 1184167 & - \\
\hline $\begin{array}{l}\text { Total nacional } \\
\text { Estados Fronterizos }\end{array}$ & 1037893 & 3775257 & 3637 & 1635341 & 1053864 & 644 & 5525367 & 1680344 & 304 & 8198701 & 6509460 & 795 \\
\hline respecto al total. & $18.25 \%$ & $19.32 \%$ & .. & $18.73 \%$ & $17.73 \%$ & . & $21.28 \%$ & $15.47 \%$ & . & $20.39 \%$ & $18.20 \%$ & - \\
\hline
\end{tabular}

FUENTE; INL, SARH, Estimaciones del SAM para zona árida y semiárida, sistema semiestabulado y de libre pastoreo, y calculos de la autora. 
CUADRO 15a. Producto interno bruto de la industria manufacturera; de la industria de alimentos y de leche y derivados. Millones de pesos, precios corrientes y a precios de 1970.

\begin{tabular}{|c|c|c|c|c|c|c|c|c|c|c|c|c|}
\hline \multirow[b]{2}{*}{ ANO } & \multicolumn{3}{|c|}{ MANUFACTURAS } & \multicolumn{3}{|c|}{ IND. DE ALIMENTOS ${ }^{1}$} & \multicolumn{3}{|c|}{$\begin{array}{l}\text { LECHE, CREMA, MANTEQUILLA } \\
\text { Y QUESO }\end{array}$} & \multicolumn{3}{|c|}{ OTROS PRODUCTES LACTEOS } \\
\hline & P. corriente & P. 1970 & $\begin{array}{c}\text { Variación } \\
\text { anual } \\
\pi\end{array}$ & P. corriente & P. 1970 & $\begin{array}{c}\text { Variación } \\
\text { anual } \\
\%\end{array}$ & P. corriente & P. 1970 & $\begin{array}{c}\text { Variación } \\
\text { anual } \\
\text { \% }\end{array}$ & P. corriente & P. 1970 & $\begin{array}{c}\text { Variación } \\
\text { anual } \\
\%\end{array}$ \\
\hline 1970 & 105203 & 105203 & - & 21327 & 21327 & $\therefore$ & 1545 & 1545 & - & 93 & 93 & - \\
\hline 1971 & 115847 & 109265 & 3.9 & 25044 & 22296 & 4.5 & 1873 & 1780 & 15.2 & 84 & 99 & 6.5 \\
\hline 1972 & 132310 & 119967 & 9.8 & 27.127 & 23369 & 4.8 & 2240 & 2029 & 14.0 & 115 & 115 & 16.2 \\
\hline 1973 & 160989 & 132552 & 10.5 & 32843 & 25125 & 7.5 & 2449 & 2148 & 5.9 & 117 & 120 & 4.4 \\
\hline 1974 & 212377 & 140963 & 6.3 & 44167 & 26227 & 4.4 & 3154 & 2358 & 9.8 & 186 & 125 & 4.2 \\
\hline 1975 & 252755 & 148058 & 5.0 & 52089 & 27619 & 5.3 & 4357 & 2390 & 1.4 & 229 & 141 & 12.8 \\
\hline 1976 & 310395 & 155517 & 5.0 & 63555 & 28965 & -1.8 & 4624 & 2536 & 6.1 & 339 & 154 & 9.2 \\
\hline 1977 & 433275 & 161037 & 3.5 & 92225 & 29668 & 9.4 & 11023 & 2726 & 1.1 & 501 & 162 & 5.2 \\
\hline 1978 & 540798 & 176817 & 9.8 & 106730 & 31283 & 5.4 & 13302 & 2937 & 7.8 & 735 & 178 & 9.9 \\
\hline 1979 & 714613 & 195614 & 10.6 & 119959 & 32889 & 5.1 & 12593 & 2964 & 0.9 & 1000 & 204 & 14.6 \\
\hline 1980 & 985013 & 209682 & 7.2 & 160573 & 34716 & 5.6 & 16663 & 2969 & 0.2 & 1468 & 223 & 9.3 \\
\hline 1981 & 1311493 & 224326 & 7.0 & 206201 & 36652 & 5.6 & 21869 & 3107 & 4.7 & 2202 & 243 & 9.0 \\
\hline 1982 & 2000786 & 217852 & -2.9 & 327504 & 38469 & 5.0 & 36320 & 3252 & 4.7 & 3513 & 232 & -4.5 \\
\hline
\end{tabular}

1 Incluye matanza de ganado,

FUENTE: SPP, INEGI, Sistema de Cuentas Nacionales de México, tl sector alimentario en Méxice. SPP. INEGI. 
CUADRO 15b. Crecimiento de la PBT de la industria de leche y productos lácteos. 1960-1975 (tasas medias anuales a precios de 1960).

\begin{tabular}{|c|c|c|c|c|c|}
\hline CLASE DE ACTIVIDAD & $\begin{array}{l}1965 \\
1960\end{array}$ & $\begin{array}{l}1970 \\
1965\end{array}$ & $\begin{array}{l}1975 \\
1970\end{array}$ & $\begin{array}{l}1970 \\
1960\end{array}$ & $\begin{array}{l}1975 \\
1960\end{array}$ \\
\hline Manufacturas & 14.8 & 8.3 & 4.2 & 11.5 & 9.1 \\
\hline Ind. de alimentos & 12.8 & 7.5 & 5.2 & 10.1 & 8.5 \\
\hline $\begin{array}{l}\text { Pasteurización/rehidratación, ho- } \\
\text { mogeneización y embotellado de }\end{array}$ & & & & & \\
\hline $\begin{array}{l}\text { leche. } \\
\text { Fabricación de crema, mantequi- }\end{array}$ & 16.9 & 21.7 & 13.8 & 19.3 & 17.4 \\
\hline $\begin{array}{l}\text { lla y queso. } \\
\text { Fabricación de leche condensa- }\end{array}$ & 25.8 & 7.8 & 1.8 & 16.4 & 10.0 \\
\hline $\begin{array}{l}\text { da, evaporada y en polvo. } \\
\text { Fabricación de flanes gelatinas }\end{array}$ & 11.9 & 6.1 & 10.2 & 9.0 & 9.4 \\
\hline $\begin{array}{l}\text { y productos similares. } \\
\text { Fabricación de cajetas, yogurts } \\
\text { y otros productos a base de le- }\end{array}$ & - & - & 12.3 & 12.0 & 12.1 \\
\hline che. & 48.4 & 11.2 & 8.2 & 28.4 & 21.6 \\
\hline
\end{tabular}

FUENTE: Elaborado por Rosa E. Montes de Oca y Gerardo Escudero, con base en los censos industriales $1960,1965,1970$ y 1975. Comercio exterior. Septiembre, 1981 p. 989. Cuadro 3.

NOTA: En 1965: La fabricación de cajetas y yogurts, etc. (2059) contiene a la de gelatinas, flanes, etc. (2054). 
CUADRO 16. Evolución del número de empresas 1970-1980.

\begin{tabular}{|c|c|c|c|c|c|c|c|}
\hline SUBSECTOR & 1970 & 1975 & 1976 & 1977 & 1978 & 1979 & 1980 \\
\hline $\begin{array}{l}\text { Pasteurización, rehidratación, } \\
\text { homogeneización y envasado } \\
\text { de leche. }\end{array}$ & 148 & 81 & 112 & 133 & 133 & 133 & 116 \\
\hline $\begin{array}{l}\text { Fabricación de leche conden- } \\
\text { sada, evaporada y en polvo. }\end{array}$ & 12 & 10 & 10 & 11 & 11 & 11 & 11 \\
\hline $\begin{array}{l}\text { Fabricación de queso, mante- } \\
\text { quilla y crema. }\end{array}$ & 340 & 361 & 386 & 399 & 414 & 412 & 431 \\
\hline Total lácteos & 500 & 452 & 508 & 543 & 558 & 556 & 558 \\
\hline
\end{tabular}

FUENTE: SPP, Censos industriales 1970 y 1975; CANACINTRA; Instituto Nacional de la Leche. SARH. Tomado de Escenarios econbmicos, SPP. 1982. 
CUADRO 17. Estructura de la industria de pasteurización, rehidratación, homogeneización y embotellado de leche, según el tamaño de los establecimientos. (porcentajes). 1970.

\begin{tabular}{|c|c|c|c|c|c|c|c|}
\hline ESTABLECIMIENTOS & $\begin{array}{l}\text { NUMERO DE ESTABLE } \\
\text { CIMIENTOS }\end{array}$ & $\begin{array}{l}\text { PERSONAL } \\
\text { OCURADO } \\
\text { (promedio) }\end{array}$ & $\begin{array}{c}\text { PAGOS TOTALES } \\
\text { AL PERSONAL }\end{array}$ & $\begin{array}{l}\text { VALOR } \\
\text { AGREGADO } \\
\text { BRUTO }\end{array}$ & $\begin{array}{c}\text { ACTIVO } \\
\text { FIJO } \\
\text { BRUTO }\end{array}$ & $\begin{array}{c}\text { PRODUCCION } \\
\text { BRUTA } \\
\text { TOTAL }\end{array}$ & $\begin{array}{c}\text { INVERSION } \\
\text { FIJA } \\
\text { BRUTA }\end{array}$ \\
\hline TOTALa & 148 & 5678 & 101396 & 374857 & 430326 & 1872595 & 51187 \\
\hline Artesanales & 4.0 & 0.2 & b & b & 0.1 & b & 0.1 \\
\hline Pequeños & 39.9 & 15.3 & 10.5 & 8.7 & 13.7 & 6.9 & 22.7 \\
\hline Medianos & 52.7 & 65.5 & 65.8 & 62.8 & 66.2 & 58.7 & 62.3 \\
\hline Grandes & 3.4 & 19.0 & 23.7 & 29.3 & 20.0 & 34.4 & 14.9 \\
\hline \multirow[t]{2}{*}{ Gigantes } & - & , & , & * & - & . & $\because$ \\
\hline & & & 1975 & & & & \\
\hline TOTAL & 81 & 6547 & 299445 & 651111 & 791009 & 5451351 & 131950 \\
\hline Artesanales & - & - & $\cdot$ & $\cdot$ & - & - & $\cdot$ \\
\hline Pequeños & 17.3 & 3.4 & 1.5 & 1.7 & 4.8 & 0.8 & 11.8 \\
\hline Medianos & 65.4 & 36.4 & 31.8 & 30.9 & 36.2 & 29.2 & 37.2 \\
\hline Grandes & 12.4 & 27.8 & 25.4 & 26.1 & 21.6 & 28.6 & 26.4 \\
\hline Gigantes & 4.9 & 32.4 & 41.3 & 41.3 & 37.4 & 41.4 & 24.6 \\
\hline
\end{tabular}

atas cifras en el renglón del total son absolutos, de las cuales se obtuvier on los porcentajes. Los datos estín expresados en miles de pesos,

Porcentaje no significativo,

*Indica que se trata de un número menor de 3 establecimientos, y para mantener la confidencialidad de los datos ćensales, se aguegan estos establecimientos al estrato anterior

FUENTE: SPP, C,GSN,I,DGE, Censos induscriales 1970 y 1975. 
LA INDUSTRIA LECHERA EN LOS ESTADOS DEL NORTE,

CUADRO 18. Empresas industrializadoras de leche en México.

\begin{tabular}{llr}
\hline \multicolumn{1}{c}{ PRODUCTO } & \multicolumn{1}{c}{ EMPRESAS } & $\begin{array}{c}\text { PARTICIPACION DE LA } \\
\text { PRODUCCION (\%) }\end{array}$ \\
\hline Leche en Polvo & Nestlé & 97 \\
& LICONSA & 3 \\
Leche condensada & Nestlé & 100 \\
Leche evaporada & Carnation & 72 \\
& LICONSA & 28 \\
Leche maternizada & Nestlé & 59 \\
& Wyth Vales & 20 \\
& Mead Johnson & 18 \\
& LICONSA & 8 \\
\hline
\end{tabular}

FUENTE: SAM, 1981. 
CUADRO 19. Pasteurización en los estados fronterizos del Norte. 1970-1980.

\begin{tabular}{|c|c|c|c|c|c|c|}
\hline \multirow[t]{2}{*}{ ENTIDAD } & \multicolumn{3}{|c|}{ No. DE PLANTAS } & \multicolumn{3}{|c|}{$\begin{array}{l}\text { VOLUMEN PRODUCIDO } \\
\text { (miles de litros) }\end{array}$} \\
\hline & 1970 & 1975 & 1980 & 1970 & 1975 & 1980 \\
\hline Coahuila & 9 & 3 & 4 & 107858 & 28835 & 68460 \\
\hline Chihuahua & 11 & 8 & 8 & 51830 & 43253 & 82892 \\
\hline Nucvo León & 17 & 8 & 6 & 79387 & 108405 & 120135 \\
\hline Tamaulipas & 11 & 6 & 5 & 2555 & 15330 & 14248 \\
\hline Baja California & 7 & 7 & 7 & 39785 & 90155 & 95321 \\
\hline Sonora & 8 & 11 & 10 & 35587 & 58400 & 63925 \\
\hline Estados Fronterizos del Norte & 63 & 43 & 40 & 317002 & 344378 & 444981 \\
\hline Total nacional & 231 & 152 & 116 & 922906 & 1323457 & 1529417 \\
\hline EFN/TOTAL & $27.3 \%$ & $28.3 \%$ & $34.5 \%$ & $34.4 \%$ & $26.0 \%$ & $29.1 \%$ \\
\hline
\end{tabular}

FUENTE: INL, SARH y SAM. 
CUADRO 20. Fabricación de crema, mantequilla y queso en los estados fronterizos del Norte. 1975.

\begin{tabular}{|c|c|c|c|c|c|c|}
\hline \multirow[t]{2}{*}{ ENTIDAD } & \multicolumn{2}{|c|}{ ESTABLECIMIENTOS } & \multicolumn{2}{|c|}{ PERSONAL OCUPADO } & \multicolumn{2}{|c|}{ PRODUCTO BRUTO TOTAL } \\
\hline & No. & $\%$ & $\begin{array}{c}\text { Total } \\
\text { (promedio) }\end{array}$ & $\%$ & $\begin{array}{c}\text { Millones de } \\
\text { pesos }\end{array}$ & $\%$ \\
\hline Coahuila & 18 & 4.99 & 179 & 5.31 & 119312 & 8.79 \\
\hline Chihuahua & 33 & 9.14 & 207 & 6.14 & 127437 & 9.39 \\
\hline Nuevo León & 17 & 4.71 & 123 & 3.65 & 56033 & 4.13 \\
\hline Mor. y Tamaulipas & 3 & 0.83 & 20 & 0.59 & 1491 & 0.11 \\
\hline Estados fronterizos & & & & & & \\
\hline del Norte & 71 & 19.7 & 529 & 15.7 & 304273 & 22.4 \\
\hline TOTAL NACIONAL & 361 & 100.0 & 3371 & 100.0 & 1357650 & 100.0 \\
\hline
\end{tabular}

FUENTE: INL, SARHSAM 